\title{
Increased salt consumption induces body water conservation and decreases fluid intake
}

\author{
Natalia Rakova, ${ }^{1,2}$ Kento Kitada, ${ }^{3}$ Kathrin Lerchl, ${ }^{2}$ Anke Dahlmann, ${ }^{2}$ Anna Birukov, ${ }^{2}$ Steffen Daub, ${ }^{3,4}$ Christoph Kopp, ${ }^{2}$ \\ Tetyana Pedchenko, ${ }^{3}$ Yahua Zhang, ${ }^{3}$ Luis Beck, ${ }^{5}$ Bernd Johannes, ${ }^{5}$ Adriana Marton, ${ }^{3}$ Dominik N. Müller, ${ }^{1}$ Manfred Rauh, ${ }^{6}$ \\ Friedrich C. Luft, ${ }^{1,3}$ and Jens Titze ${ }^{2,3}$ \\ ${ }^{1}$ Experimental and Clinical Research Center, Charité Medical Faculty and the Max-Delbrück Center for Molecular Medicine, Berlin, Germany. ${ }^{2}$ Junior Research Group 2, Interdisciplinary Center for Clinical \\ Research, University Clinic Erlangen, Erlangen, Germany. ${ }^{3}$ Division of Clinical Pharmacology, Vanderbilt University Medical Center, Nashville, Tennessee, USA. ${ }^{4}$ Department of Medicine II, University Medical \\ Center Mainz, Mainz, Germany. Institute for Aerospace Medicine, German Aerospace Center, Cologne, Germany. ${ }^{6}$ Department of Pediatrics, University Clinic Erlangen, Erlangen, Germany.
}

\begin{abstract}
BACKGROUND. The idea that increasing salt intake increases drinking and urine volume is widely accepted. We tested the hypothesis that an increase in salt intake of $6 \mathrm{~g} / \mathrm{d}$ would change fluid balance in men living under ultra-long-term controlled conditions.
\end{abstract}

METHODS. Over the course of 2 separate space flight simulation studies of 105 and 205 days' duration, we exposed 10 healthy men to 3 salt intake levels $(12,9$, or $6 \mathrm{~g} / \mathrm{d})$. All other nutrients were maintained constant. We studied the effect of salt-driven changes in mineralocorticoid and glucocorticoid urinary excretion on day-to-day osmolyte and water balance.

RESULTS. A 6-g/d increase in salt intake increased urine osmolyte excretion, but reduced free-water clearance, indicating endogenous free water accrual by urine concentration. The resulting endogenous water surplus reduced fluid intake at the 12- $\mathrm{g} / \mathrm{d}$ salt intake level. Across all 3 levels of salt intake, half-weekly and weekly rhythmical mineralocorticoid release promoted free water reabsorption via the renal concentration mechanism. Mineralocorticoid-coupled increases in free water reabsorption were counterbalanced by rhythmical glucocorticoid release, with excretion of endogenous osmolyte and water surplus by relative urine dilution. A 6-g/d increase in salt intake decreased the level of rhythmical mineralocorticoid release and elevated rhythmical glucocorticoid release. The projected effect of salt-driven hormone rhythm modulation corresponded well with the measured decrease in water intake and an increase in urine volume with surplus osmolyte excretion.

CONCLUSION. Humans regulate osmolyte and water balance by rhythmical mineralocorticoid and glucocorticoid release, endogenous accrual of surplus body water, and precise surplus excretion.

FUNDING. Federal Ministry for Economics and Technology/DLR; the Interdisciplinary Centre for Clinical Research; the NIH; the American Heart Association (AHA); the Renal Research Institute; and the TOYOBO Biotechnology Foundation. Food products were donated by APETITO, Coppenrath und Wiese, ENERVIT, HIPP, Katadyn, Kellogg, Molda, and Unilever.

\section{Introduction}

Balance studies (1-4) and direct ${ }^{23} \mathrm{Na}$ MRI measurements (5-10) suggest that humans store significant amounts of $\mathrm{Na}^{+}$in their bodies, without increasing body fluid content or body weight. We recently reported ultra-long-term balance studies in 10 healthy young men simulating a flight to Mars $(11,12)$. We found that $\mathrm{Na}^{+}$ was rhythmically stored and released with about-weekly (circaseptan) and circa-monthly (circalunar) periodicity. Rhythmical release of stored body $\mathrm{Na}^{+}$was independent of salt intake and

- Related Article: p. 1944

Related Commentary: p. 1625

Authorship note: N. Rakova and K. Kitada contributed equally to this work. Conflict of interest: The authors have declared that no conflict of interest exists. Submitted: May 17, 2016; Accepted: February 17, 2017.

Reference information: / Clin Invest. 2017;127(5):1932-1943.

https://doi.org/10.1172/JCl88530. occurred when the subjects' aldosterone excretory levels were low and glucocorticoid levels were high (11). Contrariwise, rhythmical body $\mathrm{Na}^{+}$storage occurred when aldosterone excretory levels were high and glucocorticoid levels were low. Contrary to the traditional view (13-15), these rhythmical body $\mathrm{Na}^{+}$changes occurred without parallel body weight changes, suggesting that the body maintains constant water content, while body $\mathrm{Na}^{+}$content is variable. Earlier 28-day water balance studies in humans showed about-weekly rhythmical changes in urine excretion (16). These findings led us to reinvestigate long-term control of $\mathrm{Na}^{+}$and water balance, as well as long-term $\mathrm{Na}^{+}$balance in relation to water balance in humans.

In humans, a high dietary salt intake is assumed to increase fluid intake $(15,17)$. As a result, health authorities have suggested that a salt-driven increase in soft-drink consumption could contribute to the obesity epidemic (18). However, much of the data are based on epidemiological surveys rather than direct experiments $(19,20)$. In addition, some investigators have operated on the assumption that urine volume invariably reflects fluid intake 
A
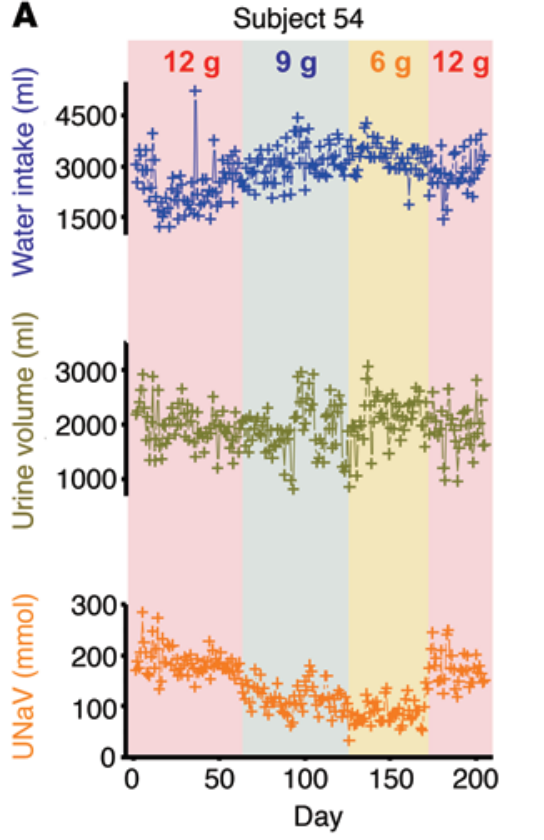
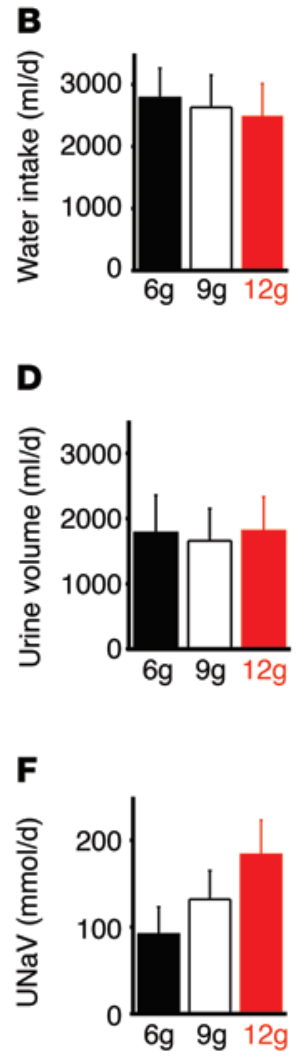
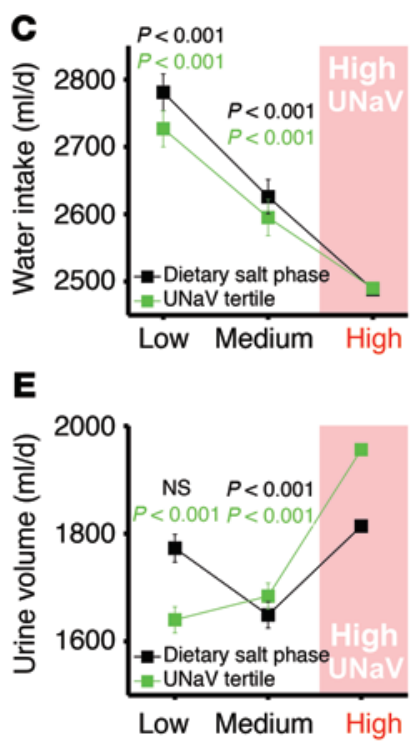

G

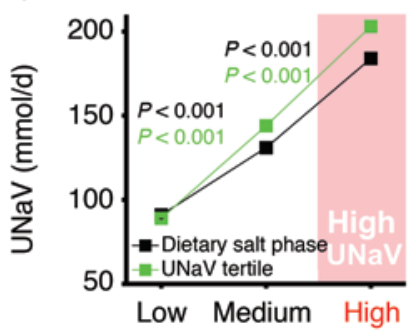

Figure 1. Time series data presentation and mixed linear model analysis to visualize the effect of increasing salt intake and the resulting $\mathrm{Na}^{+}$ excretion on water intake and urine volume formation. (A) Time series of 24-hour sodium excretion (UNaV), urine volume, and water intake in the representative subject 54 during the 205-day experiment. (B) Average fluid intake per salt intake phase in all 10 subjects $(n=1,646)$. (C) Quantification of the changes in fluid intake per salt intake phase or per 24-hour UNaV tertile. (D) Average urine volume per salt intake phase in the same subjects $(n=1,644)$. (E) Quantification of the changes in urine volume per salt intake phase or per UNaV tertile. (F) Average 24-hour UNaV per salt intake phase in the same subjects $(n=1,646)$. (C) Quantification of the changes in UNaV per salt intake phase or per UNaV tertile. Data are expressed as the average \pm $\mathrm{SD}$ (B, D, and $\mathbf{F})$ or as the $\Delta$ change \pm $\operatorname{SEM}(\mathbf{C}, \mathbf{E}$, and $\mathbf{G})$. Data were statistically analyzed by mixed linear model. Details on statistical analysis for Figure 1 are provided in the Supplemental Materials (page 28). behavior $(17,21)$. While an experimental increase in salt intake elevates fluid intake in various animal species (22-28), clinical studies have shown that varying salt intake in the range of $0.6 \mathrm{~g} / \mathrm{d}$ to $24 \mathrm{~g} / \mathrm{d}$ may not change fluid intake or urine volume in humans (29). We therefore reinvestigated the relationship between osmolyte and water balance in ultra-long-term experiments.

\section{Results}

Infradian biological variability in long-term salt and water homeostasis. In the 105-day Mars105 Study, we reduced the subjects' average daily salt intake from $12 \mathrm{~g} / \mathrm{d}(200 \mathrm{mmol} / \mathrm{d}$ sodium $)$ to $9 \mathrm{~g} / \mathrm{d}$ $(150 \mathrm{mmol} / \mathrm{d})$ and then to $6 \mathrm{~g} / \mathrm{d}(100 \mathrm{mmol} / \mathrm{d})$. In the 205-day Mars520 study, all subjects were additionally reexposed to the $12-\mathrm{g} / \mathrm{d}$ salt intake regime after salt intake had been reduced from $12 \mathrm{~g} / \mathrm{d}$ to $6 \mathrm{~g} / \mathrm{d}$ over the course of months. Long-term urinary $\mathrm{Na}^{+}$ excretion (UNaV), long-term urine volume, and long-term water intake (Figure 1A) are shown for a representative subject (see Supplemental Figure 1 for data on each individual subject; supplemental material available online with this article; https://doi.org/10.1172/ JCI88530DS1). As expected, the average daily urinary $\mathrm{Na}^{+}$excretion rapidly adjusted to the new salt intake levels. The subject exhibited additional rhythmical day-to-day variability in $\mathrm{UNaV}$ at each dietary salt intake level. This highly variable UNaV was not paralleled by obvious changes in urine volume. Furthermore, and contrary to our initial hypothesis, low $\mathrm{UNaV}$ in response to a reduction in dietary salt intake was accompanied by increased fluid intake in the subject.

We next analyzed the effect of the prescribed dietary salt intake (dietary salt phase) and 24-hour UNaV on water intake and urine volume in all subjects. The rhythmical nature of urinary $\mathrm{Na}^{+}$ excretion led to a lagged elimination of dietary salt, resulting in periodically low and high levels of salt excretion at each dietary salt intake phase, which may have masked the diuretic effect of elevated salt intake. We therefore additionally classified $\mathrm{UNaV}$ values into 3 tertiles of low, medium, and high UNaV levels to test for the effect of renal $\mathrm{Na}^{+}$elimination on water balance. We found that higher salt intake reproducibly reduced water intake (Figure 1B). Mixed linear model analysis showed that water intake was $293 \pm$ $27 \mathrm{ml} / \mathrm{d}$ higher during the $6-\mathrm{g} / \mathrm{d}$ salt intake phase than during the $12 \mathrm{~g} / \mathrm{d}$ salt intake phase (Figure 1C). Water intake in the lowest (first) tertile of $\mathrm{UNaV}$ was $237 \pm 27 \mathrm{ml} / \mathrm{d}$ higher than in the highest (third) tertile of UNaV (Figure 1C). A 6-g/d increase in salt intake did not significantly increase the urine volume (Figure 1, D and E). In contrast, urine volume in the lowest (first) tertile of $\mathrm{UNaV}$ was $316 \pm 24 \mathrm{ml} / \mathrm{d}$ lower than in the highest (third) tertile of $\mathrm{UNaV}$ (Figure 1E). We interpret this finding as showing that an increase in urinary salt excretion induced some diuresis. This salt-osmolytedriven diuretic response was often prevented at the $12-\mathrm{g} / \mathrm{d}$ salt intake level. Finally, we confirmed the accuracy of our long-term $\mathrm{Na}^{+}$balance approach. We found the expected increase of approximately $50 \mathrm{mmol} / \mathrm{d}$ in $\mathrm{UNaV}$ per salt phase when salt intake was increased by $3 \mathrm{~g} / \mathrm{d}$ (Figure $1, \mathrm{~F}$ and $\mathrm{G}$ ).

Urine osmolyte excretion induces osmolyte-free water generation in the kidneys. The renal concentration process is characterized by osmolyte excretion with parallel renal water reabsorption, resulting in a negative clearance of osmolyte-free water. We therefore next tested the hypothesis that the salt-driven increase in urine 
Table 1. Twenty-four-hour urine aldosterone excretion (UAldoV), cortisone excretion (UCortisoneV), and $\mathrm{Na}^{+}$intake per tertile of aldosterone or cortisone excretion at 3 different levels of salt intake

\begin{tabular}{|c|c|c|c|}
\hline & $\begin{array}{l}\text { UAldoV } \\
(\mu \mathrm{g} / \mathrm{d})\end{array}$ & $\begin{array}{c}\text { UCortisoneV } \\
(\mu \mathrm{g} / \mathrm{d})\end{array}$ & $\begin{array}{l}\mathrm{Na}^{+} \text {intake } \\
\text { (mmol/d) }\end{array}$ \\
\hline \multicolumn{4}{|l|}{ At $12 \mathrm{~g} / \mathrm{d}$ salt intake } \\
\hline \multicolumn{4}{|c|}{ Spontaneous variability in urine aldosterone level } \\
\hline First UAldoV tertile $(n=244)$ & $7.6 \pm 2.5$ & $78 \pm 21$ & $196 \pm 24$ \\
\hline Second UAldoV tertile $(n=254)$ & $10.5 \pm 3.1^{\complement}$ & $79 \pm 19$ & $196 \pm 25$ \\
\hline Third UAldoV tertile $(n=242)$ & $14.4 \pm 5.3^{\mathrm{C}}$ & $77 \pm 19$ & $197 \pm 22$ \\
\hline \multicolumn{4}{|c|}{ Spontaneous variability in urine cortisone level } \\
\hline First UCortisoneV tertile $(n=243)$ & $11.0 \pm 4.8$ & $60 \pm 12$ & $197 \pm 23$ \\
\hline Second UCortisoneV tertile $(n=253)$ & $10.7 \pm 4.3$ & $78 \pm 10^{c}$ & $197 \pm 23$ \\
\hline Third UCortisoneV tertile $(n=244)$ & $10.7 \pm 5.1$ & $97 \pm 15^{c}$ & $196 \pm 25$ \\
\hline
\end{tabular}

\section{At $9 \mathrm{~g} / \mathrm{d}$ salt intake}

Spontaneous variability in urine aldosterone level

\begin{tabular}{|c|c|c|c|}
\hline \\
\hline First UAldoV tertile $(n=168)$ & $10.2 \pm 3.1$ & $69 \pm 19$ & $147 \pm 21$ \\
\hline Second UAldoV tertile $(n=164)$ & $13.7 \pm 3.2^{c}$ & $69 \pm 18$ & $148 \pm 20$ \\
\hline Third UAldoV tertile $(n=167)$ & $18.2 \pm 4.4^{\complement}$ & $67 \pm 18$ & $146 \pm 21$ \\
\hline \multicolumn{4}{|c|}{ Spontaneous variability in urine cortisone level } \\
\hline First UCortisoneV tertile $(n=168)$ & $14.0 \pm 5.0$ & $54 \pm 11$ & $146 \pm 21$ \\
\hline Second UCortisoneV tertile $(n=163)$ & $14.2 \pm 4.8$ & $67 \pm 10^{c}$ & $147 \pm 20$ \\
\hline Third UCortisoneV tertile ( $n=168$ ) & $13.7 \pm 4.9$ & $84 \pm 16^{c}$ & $147 \pm 21$ \\
\hline
\end{tabular}

\section{At $6 \mathrm{~g} / \mathrm{d}$ salt intake}

Spontaneous variability in urine aldosterone level

\begin{tabular}{|c|c|c|c|}
\hline First UAldoV tertile $(n=136)$ & $11.8 \pm 3.1$ & $68 \pm 20$ & $99 \pm 22$ \\
\hline Second UAldoV tertile $(n=132)$ & $15.7 \pm 3.5^{c}$ & $69 \pm 19$ & $100 \pm 20$ \\
\hline Third UAldoV tertile $(n=135)$ & $20.3 \pm 5.0^{c}$ & $65 \pm 18^{A}$ & $102 \pm 18$ \\
\hline \multicolumn{4}{|c|}{ Spontaneous variability in urine cortisone level } \\
\hline First UCortisoneV tertile $(n=136)$ & $16.6 \pm 5.9$ & $52 \pm 13$ & $104 \pm 21$ \\
\hline Second UCortisoneV tertile $(n=132)$ & $15.7 \pm 5.1$ & $67 \pm 14^{c}$ & $99 \pm 18$ \\
\hline Third UCortisoneV tertile $(n=135)$ & $15.4 \pm 4.6^{A}$ & $84 \pm 15^{c}$ & $96 \pm 20^{B}$ \\
\hline
\end{tabular}

${ }^{A} P_{\text {(hormone tertile) }}<0.05,{ }^{\mathrm{B}} P_{\text {(hormone tertile) }}<0.01,{ }^{\mathrm{C}} P_{\text {(hormone tertile) }}<0.001$. Data are expressed as the mean $\pm S D$ and were statistically analyzed by mixed linear model. Details on statistical analysis for Table 1 are provided in the Supplemental Materials (page 292).

osmolyte excretion was coupled with enhanced free water reabsorption. We found that the sum of $2 \mathrm{Na}^{+}$concentration (2-fold $\mathrm{Na}^{+}$to account for unmeasured accompanying anions), $2 \mathrm{~K}^{+}$concentration (2-fold $\mathrm{K}^{+}$to account for unmeasured accompanying anions), and urea concentration (U[2 $\left.\left.2 \mathrm{Na}^{+} 2 \mathrm{~K}^{+} \mathrm{Urea}\right]\right)$ amounted to almost $100 \%$ of the subjects' urine solutes (Supplemental Figure 2). We show the relationship between the salt intake phase, osmolyte excretion, and free water clearance (FWC) in the same representative subject (Figure 2A). Any decrease or increase in the subject's dietary salt intake resulted in a parallel decrease or increase in his urine osmolyte excretion. The salt intake-driven changes in urine osmolyte excretion, however, were coupled with antiparallel changes in the subject's osmolyte-free water excretion in the urine. This finding, which indicates that increasing osmolyte excretion was associated with renal water conservation, was reproducible in 10 of 10 study subjects (see Supplemental Figure 3 for data on each individual subject). Quantitative analysis showed that increasing the salt intake level gradually decreased
FWC (Figure 2B). A 6-g/d increase in salt intake (corresponding to $\approx 100 \mathrm{mmol} / \mathrm{d} \mathrm{Na}^{+}$and $\left.\mathrm{Cl}^{-}\right)$decreased renal FWC by $540 \pm$ $27 \mathrm{ml} / \mathrm{d}$ (Figure 2C), while urine osmolyte excretion was increased by $201 \pm 8 \mathrm{mmol} / \mathrm{d}$ (Figure 2, D and E). Increasing osmolyte excretion and increasing $\mathrm{Na}^{+}$intake reduced FWC (Figure 2, F and G) and reduced fluid intake (Figure 1, B and C). In contrast, increasing fluid intake increased FWC (Figure 2H), indicating excretion of surplus consumed water by an intact urine dilution process.

Water intake was $32 \%$ higher than urine volume (Figure 1, B and D), indicating normal levels of insensible water loss in our subjects (25). On the assumption that $32 \%$ of the osmolyte-free water generated by the kidneys was similarly excreted by insensible water loss, the salt-driven $540-\mathrm{ml} / \mathrm{d}$ reduction in renal osmolyte-free water excretion increased our subjects' osmolytefree body water content by $-540 \mathrm{ml} / \mathrm{d} \times-1 \times 0.68=367 \mathrm{ml} / \mathrm{d}$ (Figure 3A). This projected salt-driven increase in osmolyte-free body water by improved urine concentration (Figure 3B) can reduce thirst and corresponds well to the measured $293 \pm 27 \mathrm{ml} / \mathrm{d}$ decrease in fluid intake in response to a $6-\mathrm{g} / \mathrm{d}$ increase in salt intake in our subjects. This state of affairs suggests that the physiological response to daily-life increases in salt intake in humans relies on selective renal osmolyte elimination by urine concentration, which allows maintenance of a body fluid balance in the absence of environmental water sources.

Dietary salt is excreted within the renal concentration mechanism. Figure $4 \mathrm{~A}$ shows how increasing $\mathrm{UNaV}$ led to a rise in urinary $\mathrm{Na}^{+}$concentration in our representative subject (see Supplemental Figure 4 for data on each individual subject). We next questioned which alternative urinary osmolytes might be retained and accumulated in the kidney to provide the antidiuretic driving force necessary to concentrate dietary salt in the urine. We observed an antidromic reduction in the urea and $\mathrm{K}^{+}$concentration when $\mathrm{Na}^{+}$ was concentrated in the subject's urine (Figure $4 \mathrm{~A}$ ). In all subjects, the excretion of dietary salt increased the urinary $\mathrm{Na}^{+}$and accompanying anion concentration by $98 \pm 3 \mathrm{mmol} / \mathrm{l}$ (Figure $4, \mathrm{~B}$ and C). The excretion of dietary salt by urinary concentration was paralleled by a $37 \pm 4 \mathrm{mmol} / \mathrm{l}$ reduction in the urinary urea concentration (Figure 4, D and E), while the $\mathrm{K}^{+}$concentration and accompanying anion concentration showed no reproducible changes (Figure 4, F and G). We interpret these findings as suggesting that urea accumulation in the renal interstitium provides the osmotic driving force necessary for antidiuretic water movement when dietary salt is concentrated in the urine.

Mineralocorticoid and glucocorticoid release in relation to water balance. A 6-g/d reduction in salt intake increased 24-hour urine aldosterone excretion (UAldoV) by $5.1 \pm 0.2 \mu \mathrm{g} / \mathrm{d}(P<0.001)$ and reduced 24-hour urine cortisone excretion (UCortisoneV) by 11.4 $\pm 1.0 \mu \mathrm{g} / \mathrm{d}(P<0.001)$. However, as reported earlier (11), UAldoV and UCortisoneV showed additional rhythmical half-weekly and weekly patterns of change that were independent of salt intake. This spontaneous endogenous variability led us to stratify our data into tertiles of low, medium, or high UAldoV or UCortisoneV across each salt intake level (Table 1) and to study the effect of hormone level on water balance (Table 2), as well as on osmolyte-driven urine volume formation (Table 3).

The aldosterone-driven changes in body fluid balance occurred across all 3 levels of salt intake (Table 2). The sponta- 
Table 2. Urine volume, water intake, the resulting difference, i.e., water balance gap, body weight, and urine osmolality in response to the spontaneous changes in urine aldosterone and cortisone levels at 3 different levels of salt intake

\begin{tabular}{|c|c|c|c|c|c|c|}
\hline & $\begin{array}{l}\text { Urine volume } \\
\text { (ml/d) }\end{array}$ & $\begin{array}{l}\text { Water intake } \\
(\mathrm{ml} / \mathrm{d})\end{array}$ & $\begin{array}{l}\text { Water balance gap } \\
(\mathrm{ml} / \mathrm{d})\end{array}$ & $\begin{array}{l}\text { Body weight } \\
\quad(\mathrm{kg})\end{array}$ & $\begin{array}{l}\text { Urine osmolality } \\
\text { (m0sm/kg) }\end{array}$ & $\begin{array}{l}\text { Calculated FWC } \\
(\mathrm{ml} / \mathrm{d})\end{array}$ \\
\hline \multicolumn{7}{|c|}{ Effect of urine aldosterone level ( $\Delta$ UAldoV tertiles: $6.8 \pm 0.2 \mu \mathrm{g} / \mathrm{d} ; P<0.001$ ) } \\
\hline Third UAldoV tertile $(n=244)$ & $1,702 \pm 480^{c}$ & $2,506 \pm 513^{A}$ & $804 \pm 585^{c}$ & $82.3 \pm 8.6^{c}$ & $537 \pm 177^{c}$ & $-1,118 \pm 614^{c}$ \\
\hline \multicolumn{7}{|c|}{ Effect of urine cortisone level ( $\Delta$ UCortisoneV tertiles: $36.8 \pm 0.8 \mu \mathrm{g} / \mathrm{d} ; P<0.001)$} \\
\hline First UCortisoneV tertile $(n=244)$ & $1,479 \pm 427$ & $2,492 \pm 525$ & $1,013 \pm 567$ & $81.8 \pm 8.4$ & $584 \pm 193$ & $-1171 \pm 558$ \\
\hline \multicolumn{7}{|l|}{ At $9 \mathrm{~g} / \mathrm{d}$ salt intake } \\
\hline \multicolumn{7}{|c|}{ Effect of urine aldosterone level ( $\Delta$ UAldoV tertiles: $8.0 \pm 0.2 \mu \mathrm{g} / \mathrm{d} ; P<0.001$ ) } \\
\hline First UAldoV tertile $(n=168)$ & $1,768 \pm 503$ & $2,573 \pm 537$ & $804 \pm 647$ & $81.7 \pm 7.9$ & $473 \pm 156$ & $-816 \pm 602$ \\
\hline Third UAldoV tertile $(n=168)$ & $1,544 \pm 485^{c}$ & $2,710 \pm 492^{B}$ & $1,166 \pm 561^{\complement}$ & $81.7 \pm 7.7$ & $533 \pm 184^{c}$ & $-961 \pm 553^{B}$ \\
\hline \multicolumn{7}{|c|}{ Effect of urine cortisone level ( $\Delta$ UCortisoneV tertiles: $30.9 \pm 0.8 \mu \mathrm{g} / \mathrm{d} ; P<0.001)$} \\
\hline First UCortisoneV tertile $(n=168)$ & $1,392 \pm 453$ & $2,613 \pm 504$ & $1,221 \pm 566$ & $81.6 \pm 7.8$ & $568 \pm 202$ & $-997 \pm 539$ \\
\hline First UAldoV tertile $(n=136)$ & $1,886 \pm 576$ & $2,764 \pm 526$ & $878 \pm 687$ & $79.9 \pm 7.2$ & $412 \pm 172$ & $-436 \pm 744$ \\
\hline Third UAldoV tertile $(n=136)$ & $1,660 \pm 570^{c}$ & $2,805 \pm 443$ & $1,145 \pm 601 c$ & $80.3 \pm 7.3^{8}$ & $459 \pm 181^{B}$ & $-600 \pm 672^{\mathrm{B}}$ \\
\hline \multicolumn{7}{|c|}{ Effect of urine cortisone level ( $\Delta$ UCortisoneV tertiles: $32.0 \pm 0.8 \mu \mathrm{g} / \mathrm{d} ; P<0.001$ ) } \\
\hline First UCortisoneV tertile $(n=136)$ & $1,449 \pm 495$ & $2,783 \pm 438$ & $1,334 \pm 510$ & $80.2 \pm 7.2$ & $507 \pm 198$ & $-738 \pm 604$ \\
\hline Third UCortisoneV tertile $(n=136)$ & $2,112 \pm 514^{\complement}$ & $2,776 \pm 518$ & $663 \pm 604^{c}$ & $80.0 \pm 7.1$ & $369 \pm 132^{c}$ & $-302 \pm 780^{c}$ \\
\hline
\end{tabular}

${ }^{\mathrm{A}} P_{\text {(hormone tertile) }}<0.05,{ }^{\mathrm{B}} P_{\text {(hormone tertile) }}<0.01,{ }^{\mathrm{C}} P_{\text {(hormone tertile) }}<0.001$. Data are expressed as the mean \pm SD and were statistically analyzed by mixed linear model analysis. Details on statistical analysis for Table 2 are provided in the Supplemental Materials (page 460). FWC was calculated as follows: urine volume $\times$ (1 - UOsmo/POsmo), with an estimated constant plasma osmolality of $300 \mathrm{mOsm} / \mathrm{kg}$. UOsmo, urine osmolality; POsmo, plasma osmolality.

neously rhythmical $7.6 \pm 0.2 \mu \mathrm{g} / \mathrm{d}$ UAldoV increase reduced urine volume by $219 \pm 25 \mathrm{ml} / \mathrm{d}\left(P_{\text {(aldosterone) }}<0.001\right)$ and increased fluid intake by $95 \pm 27 \mathrm{ml} / \mathrm{d}\left(P_{\text {(aldosterone) }}<0.01\right.$; Figure $\left.5 \mathrm{~A}\right)$. The resulting increase in water balance was coupled with a measurable body weight increase in the subjects $\left(+0.41 \pm 0.10 \mathrm{~kg} ; P_{\text {(aldosterone) }}\right.$ $<0.001)$. We interpret these findings as indicating that the high mineralocorticoid levels induced body fluid retention.

We next studied the role of the rhythmical effect of aldosterone on the urinary concentrating mechanism. Across all levels of salt intake, the highly rhythmical UAldoV levels reduced $2 \mathrm{UNaV}$ by $58.9 \pm 6.1 \mathrm{mmol} / \mathrm{d}\left(P_{\text {(aldosterone) }}<0.001\right)$. However, this aldosteronedriven reduction in urine $\mathrm{Na}^{+}$excretion did not significantly reduce the sum excretion of $\mathrm{Na}^{+}, \mathrm{K}^{+}$, and urea osmolytes in the urine $(-16.0 \pm 8.9 \mathrm{mmol} / \mathrm{d}, P=0.07)$, because high aldosterone levels increased $2 \mathrm{UKV}$ by $22.6 \pm 2.1 \mathrm{mmol} / \mathrm{d}\left(P_{\text {(aldosterone) }}<0.001\right)$ as well as urinary urea excretion by $20.7 \pm 3.3 \mathrm{mmol} / \mathrm{d}\left(P_{\text {(aldosterone) }}<\right.$ 0.001). High excretory aldosterone levels instead were associated with an increase in the urine concentration of $53 \pm 7 \mathrm{mOsm} / \mathrm{kg}$ $\left(P_{\text {(aldosterone) }}<0.001\right)$. The well-known antidiuretic effect of aldosterone thus became clinically visible within the context of the urine concentration mechanism by reduced FWC (Table 2). This effect resulted in predominant osmolyte-free water reabsorption (see the supplemental calculations in the Supplemental Materials and Figure 5A).

The glucocorticoid-associated changes in body fluid balance occurred across all 3 levels of salt intake (Table 2). Rhythmical ele- vation of urinary cortisone excretory levels by $33.8 \pm 0.7 \mu \mathrm{g} / \mathrm{d}(P<$ $0.001)$ was linked with increases in urine volumes of $627 \pm 20 \mathrm{ml} / \mathrm{d}$ $\left(P_{\text {(cortisone) }}<0.001\right)$, without quantifiable changes in fluid intake $\left(P_{\text {(cortisone) }}=0.67\right.$; Figure $\left.5 \mathrm{~B}\right)$. However, the resulting negative renal fluid balance was not accompanied by changes in body weight $\left(P_{\text {(cortisone) }}=0.25\right)$. This state of affairs suggests that the water surplus that was excreted when glucocorticoid levels were high had been generated endogenously. The renal water conservation mechanism did not contribute to endogenous water generation when glucocorticoid levels were high. The rhythmical increase in UCortisoneV was associated with increased urinary $2 \mathrm{Na}^{+}, 2 \mathrm{~K}^{+}$, and urea excretion across all 3 levels of salt intake (Table 3 ), resulting in an increase of $114.0 \pm 8.5 \mathrm{mmol} / \mathrm{d}$ in the sum of $2 \mathrm{Na}^{+}, 2 \mathrm{~K}^{+}$, and urea osmolyte excretion in the urine $\left(P_{\text {(cortisone) }}<0.001\right)$. High rhythmical glucocorticoid levels were additionally linked with a reduction of $126 \pm 7 \mathrm{mmol} / \mathrm{l}$ in the sum of $2\left[\mathrm{Na}^{+}\right], 2\left[\mathrm{~K}^{+}\right]$, and [Urea] osmolyte concentrations $\left(P_{\text {(cortisone) }}<0.001\right)$. Rhythmical glucocorticoid release was therefore linked to increased diuresis in the context of the urine dilution mechanism by increasing FWC (Table 2). The clinical readout was predominant osmolyte-free water excretion (see the supplemental calculations in the Supplemental Materials and Figure 5B).

Projected and measured salt-induced change in water balance. A 6-g/d increase in salt intake reduced UAldoV excretion by $5.1 \pm 0.2$ $\mu \mathrm{g} / \mathrm{d}$. The high salt intake thus reduced the level of spontaneously rhythmical $7.6 \pm 0.2 \mu \mathrm{g} / \mathrm{d}$ UAldoV release by $73 \%$, resulting in a projected $-5.1 / 7.6=-0.67$-fold change in water intake, urine excre- 
Table 3. Osmolyte excretion and osmolyte concentration in response to the spontaneous changes in urine aldosterone and cortisone levels at 3 different levels of salt intake

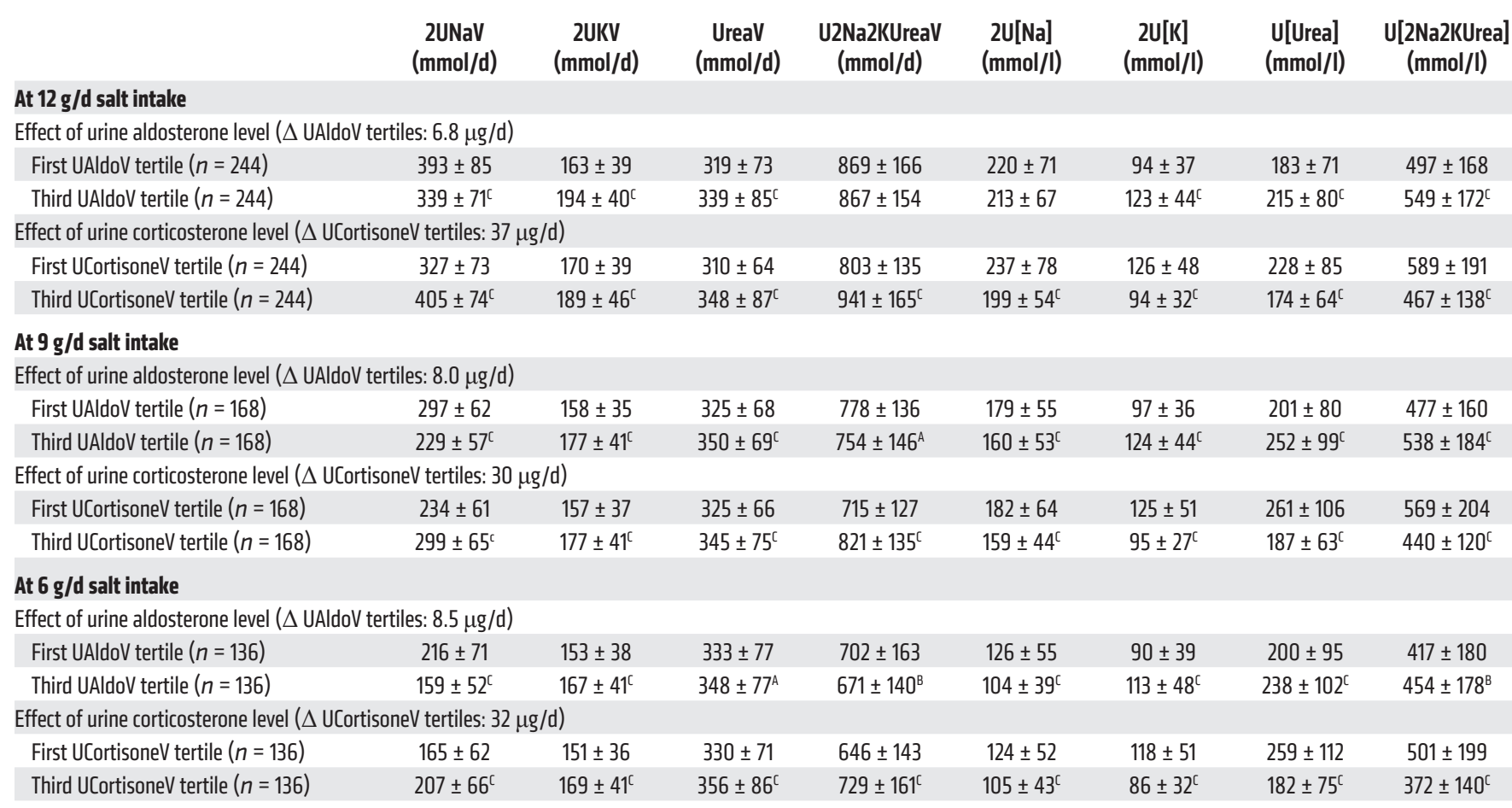

${ }^{\mathrm{A}} P_{\text {(hormone tertile) }}<0.05,{ }^{\mathrm{B}} P_{\text {(hormone tertile) }}<0.01,{ }^{\mathrm{C}} P_{\text {(hormone tertile) }}<0.001$. Data are expressed as the mean $\pm \mathrm{SD}$ and were statistically analyzed by mixed linear model. Details on statistical analysis for Table 3 are provided in the Supplemental Materials (page 748).

tion, water balance, and body weight (Supplemental Figure 5). In contrast, a 6-g/d increase in salt intake increased UCortisoneV excretion by $11.4 \pm 1.0 \mu \mathrm{g} / \mathrm{d}$. The high salt intake thus increased the level of spontaneously rhythmical $33.8 \pm 0.7 \mu \mathrm{g} / \mathrm{d}$ UCortisoneV release by $38 \%$, resulting in a projected $11.4 / 33.8=0.34$-fold change in water intake, urine excretion, water balance, and body weight (Supplemental Figure 5).

Calculation of the combined effect of salt-driven mineralocorticoid suppression and glucocorticoid activation (Supplemental Figure 6) showed a projected $358-\mathrm{ml} / \mathrm{d}$ increase in urine volume formation in response to a $6-\mathrm{g} / \mathrm{d}$ increase in salt intake, which was associated with a projected $-60 \mathrm{ml} / \mathrm{d}$ decrease in fluid intake (Figure 5C). These results suggest that increased glucocorticoid activity was associated with excretion of an endogenously generated water surplus at the high salt intake level. This projected saltdriven modulation of mineralocorticoid- and glucocorticoidmediated adjustment of body water balance corresponded well with the measured $316 \pm 24 \mathrm{ml} / \mathrm{d}$ increase in urine volume and the $546 \pm 34 \mathrm{ml} / \mathrm{d}$ reduction in the water balance gap between fluid intake and urine volume in the third tertile of $\mathrm{UNaV}$ excretion (Figure 5, C and D). The 24-hour negative water balance in the third tertile of UNaV excretion was preceded by an increase in body weight of $882 \pm$ $99 \mathrm{~g}$ on the morning before the start of the 24-hour collection period (Figure 5D). This state of affairs suggests that increased urine volume formation and reduced fluid intake in the third tertile of $\mathrm{UNaV}$ excretion characterize the release of surplus salt osmolytes, together with a preexisting endogenous water surplus within the following 24-hour urine collection period.

\section{Discussion}

We show that long-term water balance in humans is regulated by spontaneously rhythmical mineralocorticoid-coupled osmolytefree water accrual, which results in a body water surplus, and by spontaneously rhythmical glucocorticoid-coupled osmolyte-free water excretion for elimination of the water surplus. We have reported previously that rhythmical about-half weekly (circasemiseptan) and about-weekly (circaseptan) aldosterone and cortisone release occurred independently of salt intake at each dietary salt intake level (11). We now show that this infradian rhythmical physiological regulatory pattern is linked to periodical generation of an endogenous water surplus. The process occurs via timedependent mineralocorticoid release and promotion of antidiuresis, which alternates with time-dependent glucocorticoid release and promotion of diuresis and excretion of an endogenous water surplus. The obvious advantage of this endogenously driven generation and release of osmolyte-free water within the renal concentration or dilution mechanism is that long-term maintenance of body fluid homeostasis in humans may be less dependent on external water sources than is currently believed.

The physiological principle of water conservation within the renal concentration mechanism is that the excretion of surplus osmolytes is coupled with antidromic water conservation by reducing renal FWC. We show that increasing salt intake from $6 \mathrm{~g} / \mathrm{d}$ to 
A

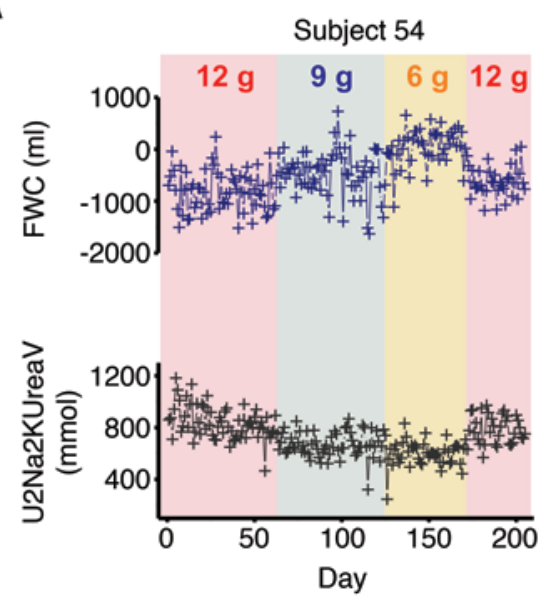

B

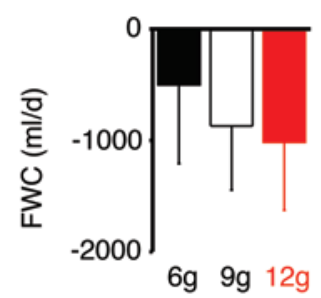

D

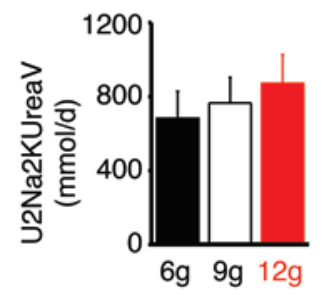

C

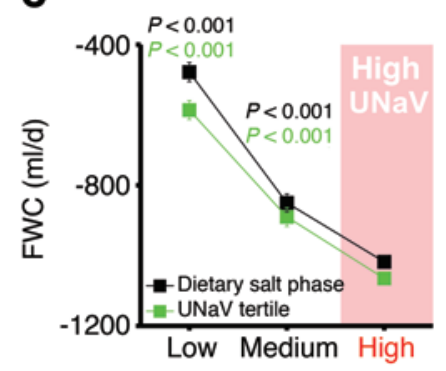

E

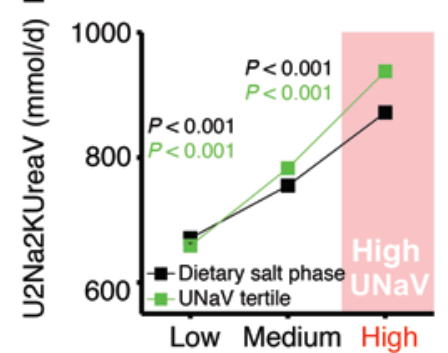

H

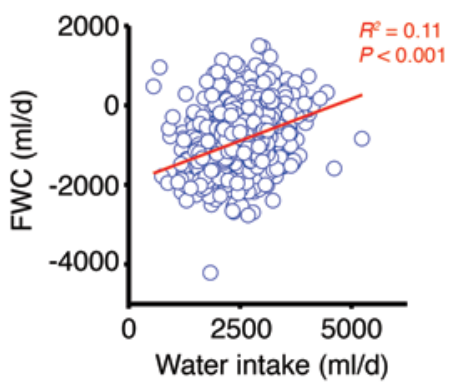

Figure 2. Time series data presentation and mixed linear model analysis to visualize the effect of increasing salt intake and the resulting $\mathrm{Na}^{+}$excretion on free water accrual by urine concentration. (A) Time series of the sum of 24 -hour urine $\mathrm{Na}^{+}$(with accompanying anions), $\mathrm{K}^{+}$(with accompanying anions), and urea osmolyte excretion (U2Na2KUreaV) and FWC in the representative subject 54 during the 205-day experiment. (B) Average FWC per salt intake phase in all 10 subjects $(n=1,644)$. (C) Quantification of the changes in FWC per salt intake phase or per 24-hour UNaV tertile. (D) Average urine osmolyte excretion (U2Na2KUreaV) per salt intake phase in the same 10 subjects $(n=1,646)$. (E) Quantification of the changes in urine osmolyte excretion per salt intake phase or per 24-hour UNaV tertile. (F-H) Relationship among 24-hour osmolyte excretion, designated 24-hour Na+ intake, designated 24-hour fluid intake, and 24-hour FWC in the urine. Data are expressed as the average \pm SD (B and $\mathbf{D}$ ) or as the $\Delta$ change \pm SEM (C and E). Data were statistically analyzed by mixed linear model (C and $\mathbf{E}$ ) or simple linear regression $(\mathbf{F}-\mathbf{H})$. Details on statistical analysis for Figure 2 are provided in the Supplemental Materials (page 64).

$12 \mathrm{~g} / \mathrm{d}$ led to endogenous osmolyte-free water accrual. The 6-g/d increase in salt intake decreased osmolyte-free water excretion by $540 \pm 27 \mathrm{ml} / \mathrm{d}$ and resulted in the successful generation of an endogenous osmolyte-free water surplus. This water accrual process was so effective that a body water surplus was available at the $12-\mathrm{g} / \mathrm{d}$ salt intake level and could be excreted and thereby increase the urine volume. The endogenous nature of this water surplus explains the seemingly counterintuitive finding that the excretion of a $\mathrm{Na}^{+}$and $\mathrm{Cl}^{-}$osmolyte surplus of $201 \pm 8 \mathrm{mmol} / \mathrm{d}$ at the $12-\mathrm{g} / \mathrm{d}$ salt intake level eventually reduced fluid intake, even though urine volume was increased. We conclude that the primary physiological response of the body to increased salt intake in our subjects was an antidromic management of osmolyte and water balance; osmolytes were excreted and water was retained. Thus, the kidneys acted as a biological barrier designed for water conservation. This barrier functionally separates osmolytes from water to prevent dehydration while conducting osmolyte balance. These renal changes occurred at a urine osmolality of approximately 500 to $600 \mathrm{mOsm} / \mathrm{kg}$, which is not near the maximal values of more than $1,000 \mathrm{mOsm} / \mathrm{kg}$ for humans. This concentration maximum leaves a much wider range for endogenous water accrual before increased fluid intake in response to increased salt intake were to become necessary.

The idea is well accepted that increased salt intake induces thirst, thereby leading to increased fluid intake and secondary parallel elimination of the ingested excess salt and fluid in the urine $(14,15,30)$ and supports arguments favoring strategies directed at reducing dietary salt intake in the population $(18,21)$. To test this hypothesis, we selected salt intake levels of $12 \mathrm{~g} / \mathrm{d}$, the value identified in the international worldwide INTERSALT study of approximately $9 \mathrm{~g} / \mathrm{d}$ (31), as well as the value of $6 \mathrm{~g} / \mathrm{d}$ or less recommended by guidelines committees (32). The fact that increasing salt intake may not increase fluid intake or urine volume has been demonstrated earlier in shorter sodium and water balance studies. Luft et al. varied daily salt intake from $10 \mathrm{mmol} / \mathrm{d}$ to 200 and $400 \mathrm{mmol} / \mathrm{d}$ for 7 days and found no influence of dietary salt intake levels on water intake or urine volume (29). Even increas- 
A

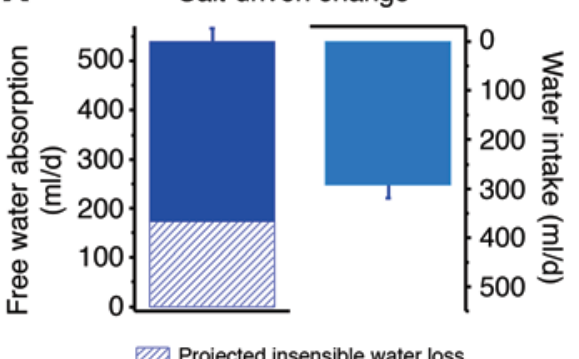

Projected insensible water loss
B

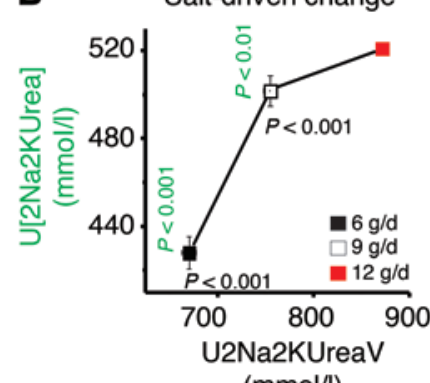

(mmol/l)

Figure 3. Salt-driven changes in FWC, fluid intake, urine osmolyte excretion, and urine osmolyte concentration. (A) Effect of a $6-\mathrm{g} / \mathrm{d}$ increase in salt intake on 24-hour FWC and 24-hour fluid intake in the 10 subjects. (B) Effect of 6-g/d, 9-g/d, and 12-g/d salt intake on 24-hour osmolyte excretion (U2Na2KUreaV; $n=1,646$ ) and osmolyte concentration in the 24-hour urine samples (U[2Na2KUrea]; $n=1,636$ ) for the 10 subjects. Data were statistically analyzed by mixed linear model and are expressed as the $\Delta$ change \pm SEM. Details on statistical analysis for Figure 3 are provided in the Supplemental Materials (page 100). The projected insensible water loss was estimated from the measured difference between fluid intake and urine volume in all subjects and at all phases of salt intake.

ing salt intake to $660 \mathrm{mmol} / \mathrm{d}$ did not lead to detectable increases in urine volume in humans during completely controlled 4-weeklong metabolic ward experiments (4), albeit with a fixed fluid intake maintained at $40 \mathrm{ml} / \mathrm{kg} / \mathrm{d}$.

Studies of the relationship between dietary salt ingestion and changes in urine volume without parallel measurement of fluid intake show divergent results. He et al. found increases in urine volume with increasing salt intake in clinical studies of hypertensive women and men under daily life conditions (17), which were similar to our results. In contrast, and in line with Luft's earlier study (29), the Dietary Approaches to Stop Hypertension (DASH) salt intake trial, in which UNaV was reduced from $159 \pm$ $5 \mathrm{mmol} / \mathrm{d}$ to $67 \pm 4 \mathrm{mmol} / \mathrm{d}$ by dietary salt reduction, indicated that dietary salt was concentrated in the urine, with no changes in urine volume (33). We have shown earlier that excretion of dietary salt in our subjects was characterized by half-weekly and weekly rhythmically changing patterns (11). The resulting rhythmical $\mathrm{Na}^{+}$ storage and release reduced the predictive value of an accurately collected 24-hour urine sample to correctly estimate a 3-g/d difference in salt intake to only 50\% (12). Therefore, quantification of $\mathrm{Na}^{+}$osmolyte excretion in the urine, and not of salt intake levels, was necessary to detect the effect of dietary salt intake on urine volume formation in our subjects. We are not convinced that epidemiological studies and information policy, which rely on associations among food intake, beverage consumption, and salt content in the urine to study a functional relationship among salt intake, soft drink consumption, and obesity in populations, rest on valid physiological and methodological assumptions (18, $19,21)$. The fact that a $6-\mathrm{g} / \mathrm{d}$ increase in salt intake led to surplus body water without increasing fluid intake has prompted us to propose an alternative view on the long-term control of body fluids in humans with increased osmolyte excretion. We present our interpretation as 3 interconnected hypotheses.

Hypothesis 1: Increasing salt intake promotes accrual of endogenous water. This hypothesis is based on 3 findings. First, the longterm physiological pattern of increased $\mathrm{Na}^{+}$(with anions), $\mathrm{K}^{+}$(with anions), and urea excretion was coupled with decreased FWC in 10

of 10 study subjects. This water conservation principle with increased osmolyte excretion occurred spontaneously at each of our 3 dietary salt intake levels and was more likely to occur at the $12-\mathrm{g} / \mathrm{d}$ salt intake level, when the dietary salt-induced $\mathrm{Na}^{+}$and $\mathrm{Cl}^{-}$osmolyte surplus of $201 \pm 8 \mathrm{mmol} / \mathrm{d}$ was released. Second, the resulting body water accrual pattern during states of surplus osmolyte excretion such as that occurring with increased dietary salt intake is apparently efficient enough to generate an endogenous, fluid intakeindependent water surplus, as demonstrated by a quantifiable increase in body weight despite decreased fluid intake. Third, all study subjects excreted the dietary $\mathrm{Na}^{+}$within the urine concentration process. This physiological principle of dietary salt excretion has been demonstrated previously: excess dietary salt was concentrated in the urine in the DASH study (31), as well as in the clinical salt-loading study by Luft et al. (27). In addition, our data suggest that the more negative FWC needed to concentrate salt osmolytes in the urine requires the accumulation of other osmolytes in the renal interstitium to provide the alternative osmotic driving force necessary to reabsorb water and counterbalance the osmotic-diuretic effect of salt osmolyte excretion. We show that the concentration of dietary salt in the urine was characterized by a predominantly reduced urinary urea concentration. These findings suggest that, in states of high dietary salt excretion, humans accumulate urea osmolytes in the renal medulla to support the renal concentration mechanism and thereby successfully reabsorb water. Similarly, as demonstrated earlier by McCance and Widdowson (26), urea-driven fluid retention may limit renal water loss during exercise-induced water loss from the skin. The idea that increased salt intake modulates such natriuretic-ureotelic regulation of body fluids suggests that a major regulatory pattern of dietary salt excretion involves renal elimination of osmolytes, which is coupled with urea-driven, osmolyte-free fluid retention to prevent salt-driven osmotic diuresis and dehydration (Supplemental Figure 7).

Hypothesis 2: Dietary salt modulates endogenous infradianrhythmical control of osmolyte and water accrual and release. This hypothesis is based on 3 findings. First, across all 3 salt intake levels and independent of salt intake, spontaneously rhythmical aldosterone release was linked to $\mathrm{Na}^{+}$reabsorption and antidiuresis, favoring a body water surplus with a measurable increase in body weight, primarily by free water reabsorption. These effects occurred within the renal concentration mechanism. Second, across all 3 salt intake levels, and therefore not primarily dependent on salt intake, spontaneously rhythmical glucocorticoid release was linked to the excretion of all 3 major osmolytes and their accompanying anions and was associated with urine formation by relative urine dilution. The linkage between increased glucocorticoid excretion and osmolyte-free water excretion occurred in the absence of increased fluid intake, indicating excretion of a previously generated water surplus. Third, a 6-g/d increase in salt intake reduced the level of spontaneously rhythmical endogenous mineralocorticoid hormone release and increased the level of spontaneously rhythmical endogenous glucocorticoid hormone release. We show that the projected combined effect of salt- 
A
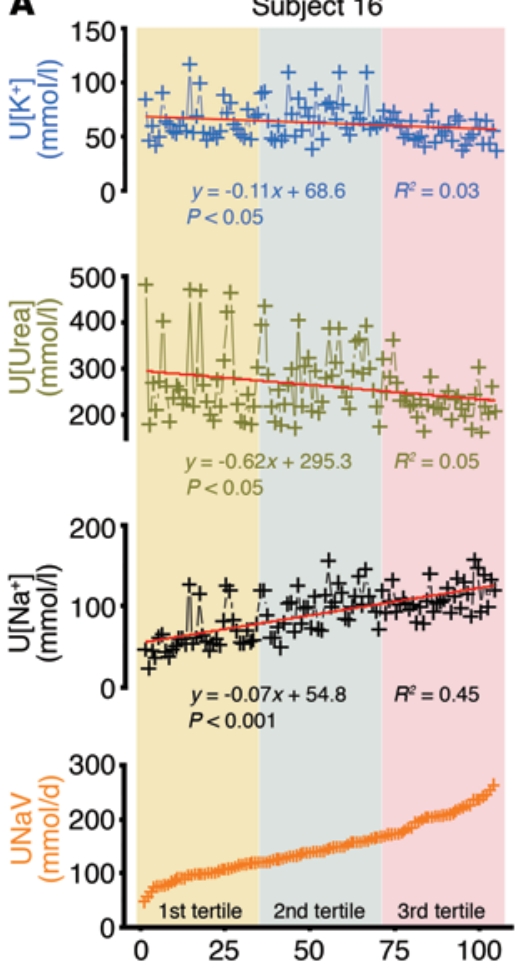

Parameters sorted for increasing UNaV
B

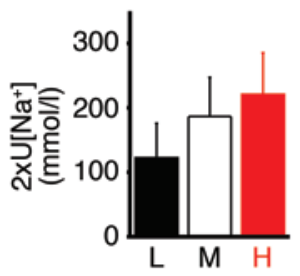

D

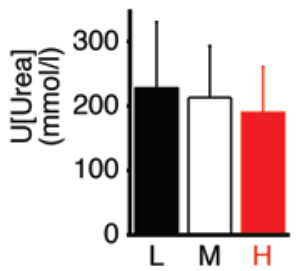

$\mathbf{F}$

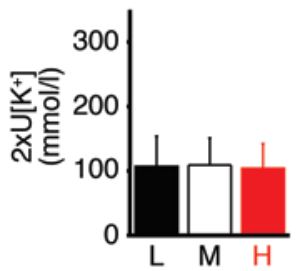

C

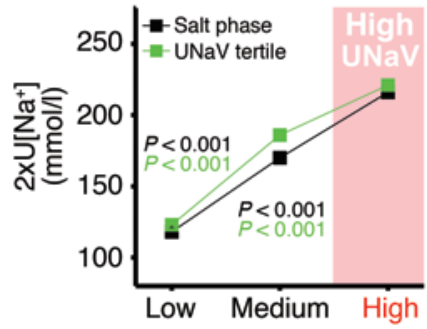

$\mathbf{E}$
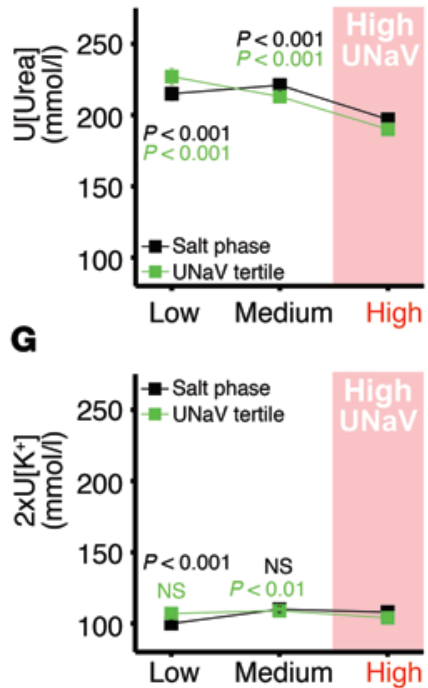

Figure 4. Effect of increasing 24-hour urine $\mathrm{Na}^{+}$excretion on urine $\mathrm{Na}^{+}$, urea, and $\mathrm{K}^{+}$concentration. To quantify the effect of increasing urine $\mathrm{Na}^{+}$excretion on urine osmolyte concentration, the data are depicted and analyzed per tertile of urine $\mathrm{Na}^{+}$excretion. (A) Twenty-four-hour UNaV tertiles and their relation to urine $\mathrm{Na}^{+}$concentration $\left(\mathrm{U}\left[\mathrm{Na}^{+}\right]\right)$, urine urea concentration (U[Urea]), and urine $\mathrm{K}^{+}$concentration $\left(\mathrm{U}\left[\mathrm{K}^{+}\right]\right)$in the representative subject 16 during the 105-day experiment. (B) Average urine $2 \times \mathrm{Na}^{+}$concentration per salt intake phase in the 10 subjects $(n=1,644)$. (C) Quantification of the changes in urine $\mathrm{Na}^{+}$concentration per salt intake phase or per 24-hour UNaV tertile. (D) Average urine urea concentration per salt intake phase $(n=1,636)$. (E) Quantification of the changes in urine urea concentration per salt intake phase or per 24 -hour UNaV tertile. (F) Average urine $2 \times \mathrm{K}^{+}$concentration per salt intake phase $(n=1,644)$. (C) Quantification of the changes in urine $\mathrm{K}^{+}$concentration per salt intake phase or per 24 -hour UNaV tertile. Data are expressed as the average \pm SD (B, D, and $\mathbf{F}$ ) or as the $\Delta$ change \pm SEM (C, E, and $\mathbf{G})$. Data were statistically analyzed by mixed linear model. Details on statistical analysis for Figure 4 are provided in the Supplemental Materials (page 112). L, low; M, medium; H, high.

driven suppression of rhythmical mineralocorticoid release and promotion of rhythmical glucocorticoid release predicts a negative renal fluid balance, with reduced fluid intake, increased urine volume, and reduced body weight. This projected hormonedriven effect on fluid balance corresponds well to the measured negative renal water balance in the third tertile of renal $\mathrm{Na}^{+}$ excretion. This observation suggests that long-term water balance critically relies on rhythmical mineralocorticoid and glucocorticoid hormone action. In contrast to the predicted combined hormone-driven effect, the relative dominance of the glucocorticoid-associated osmolyte and water excretion pattern in the third tertile of UNaV excretion was characterized by a measured increase in body weight, and not by a reduction in body weight. We interpret this finding as indicating that high glucocorticoid levels occur when increased osmolyte intake and increased endogenous water accrual have led to a surplus in body osmolyte and water content that requires excretion (Supplemental Figure 8).

Hypothesis 3: High salt intake induces glucocorticoid-driven metabolic water production. This hypothesis is based on 3 findings. First, a $6-\mathrm{g} / \mathrm{d}$ increase in salt intake not only suppressed urinary aldoste- rone excretion, but also increased cortisol and cortisone excretion in the urine (11). This finding is in line with the study by Kerstens et al. that examined the effect of dietary salt ingestion on glucocorticoid excretion in salt-resistant subjects under daily life conditions (34). Thus, a 6-g/d increase in salt intake induces a catabolic hormone profile in humans. Second, we found that high glucocorticoid levels occurred with increased $\mathrm{Na}^{+}, \mathrm{K}^{+}$, and urea osmolyte excretion. However, protein intake was constant during the study. Urea is generated from exogenous or endogenous protein sources. This process is energy intensive and utilizes 3 moles ATP per mole of generated urea osmolyte. The increased urea excretion at a constant protein intake level therefore suggests that the catabolic hormone profile predisposed the subjects to increases in urea production with higher energy expenditure when their salt intake was elevated. Third, approximately $90 \%$ of the diuretic response observed with high glucocorticoid levels was osmolyte-free water excretion, which occurred in the absence of increased water intake and resulted in a negative renal water balance. Increased body weight in the morning preceded a negative water balance within the next 24 hours. Thus, a 24-hour water balance at high levels of 
A Mineralocorticoid-driven change in water balance

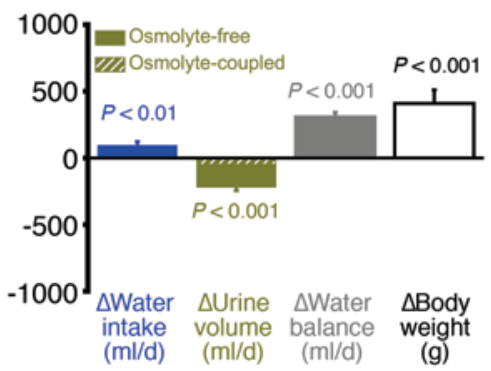

B Glucocorticoid-driven change in water balance

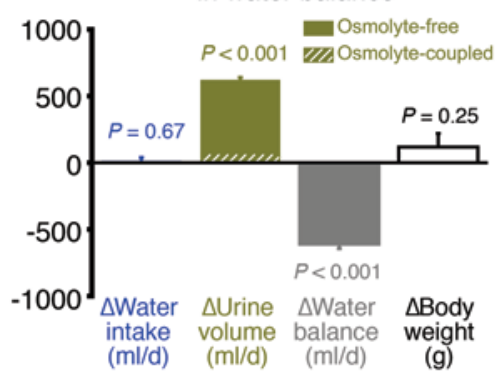

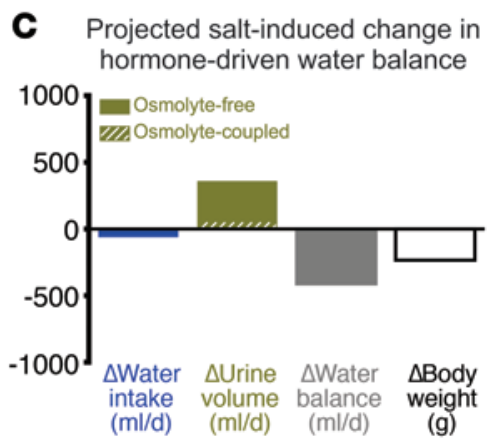
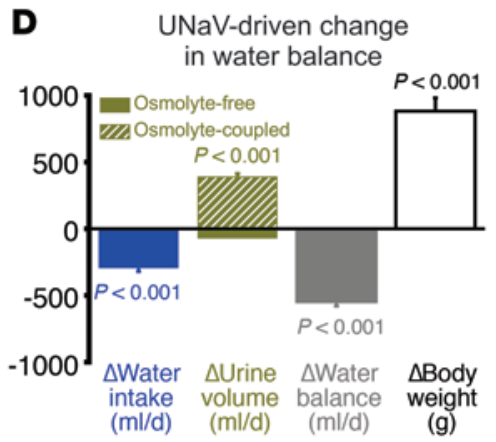

Figure 5. Long-term rhythmical hormonal control of water balance and its modulation by dietary salt intake. (A) Effect of rhythmical mineralocorticoid release, independent of salt intake, on water intake $(n=1,646)$, urine volume $(n=1,644)$, renal water balance $(n=1,646)$, and body weight $(n=1,631)$. (B) Effect of rhythmical glucocorticoid release, independent of salt intake, on water intake $(n=1,646)$, urine volume $(n=1,644)$, renal water balance $(n=1,646)$, and body weight $(n=1,631)$. (C) Projected combined effect of salt-driven modulation of rhythmical mineralocorticoid and glucocorticoid release on water intake, urine volume, renal water balance, and body weight. (D) Measured effect of third tertile $\mathrm{Na}^{+}$excretion in the urine on water intake $(n=1,646)$, urine volume $(n=1,644)$, renal water balance $(n=1,646)$, and body weight $(n=1,631)$. Data were statistically analyzed by mixed linear model and are expressed as the $\Delta$ change \pm SEM (A, B, and D). The projected combined effect of mineralocorticoid suppression and glucocorticoid increase by dietary salt intake in $\mathbf{C}$ was calculated from the data presented in $\mathbf{A}$ and $\mathbf{B}$ and the measured suppression of mineralocorticoid and increase in glucocorticoid levels by a $6-\mathrm{g} / \mathrm{d}$ increase in salt intake. Details on the supplemental calculations and statistical analyses pertaining to Figure 5 are provided in the Supplemental Materials (pages 22 and 148, respectively).

glucocorticoid excretion occurred with excretion of a surplus of free water, which had not been accrued by drinking water. This free water surplus may have been acquired earlier as a result of successful free water reabsorption. In addition, increased rhythmical glucocorticoid action may increase metabolic water production by promoting protein, fat, and sugar breakdown.

Limitations. We showed that a 6-g/d increase in salt intake leads to osmolyte excretion and renal water conservation in humans, resulting in endogenous generation of a water surplus that reduces thirst and fluid intake. However, we cannot provide information as to what extent the changes in insensible water loss or metabolic water production contributed to the generation of the body water surplus. Normal adults usually ingest 1.5-2.5 liters of water per day; the corresponding urine volume is 1-2 liters per day, assuming the usual low rate of insensible losses via the skin, lungs, and intestines (25). The average water intake levels and urine excretion data from our study are in agreement with this textbook assumption (Figure 1). Most of this insensitive water loss occurs via the skin and lungs. At constant ambient room temperature $\left(20^{\circ} \mathrm{C}\right)$ and humidity
(40\%-65\%), the average transepidermal water loss in resting adults is approximately $10 \mathrm{~g} / \mathrm{m}^{2} / \mathrm{h}(23,28,35)$, corresponding to approximately $500 \mathrm{ml} / \mathrm{d}$ in our subjects. If increased salt intake had promoted osmolytefree water conservation not only in the kidney barrier, but also simultaneously in the epithelial skin barrier, an unmeasured reduction in skin water loss could have significantly contributed to the body water surplus detected in our subjects. Similarly, we have no information on differential osmolyte and water handling in the lungs and intestinal barrier. These sites, while possibly important, require additional experiments beyond the scope of the present study.

While a $6-\mathrm{g} / \mathrm{d}$ increase in salt intake increased glucocorticoid levels and therefore induced a relatively catabolic hormone profile, we cannot provide direct or indirect measurements of metabolic water production at the tissue level. In the absence of indirect calorimetric measurements, molecular glucocorticoid receptor-binding studies, and MRI-based body composition studies, we can only hypothesize that the saltdriven increase in glucocorticoid levels led to increased breakdown of cellular fuels and increased metabolic water production, thereby contributing to the body water surplus observed in our subjects. We addressed this limitation in additional animal experiments and showed that a high-salt diet can increase corticosterone release and thereby induce a catabolic state, with increased fatty acid oxidation and exploitation of muscle nitrogen stores for urea osmolyte generation.

The experimental design of our study did not allow us to investigate the role of vasopressin release. In response to small increases in plasma osmolality, vasopressin release occurs before thirst is triggered. This neuroendocrine hormone system could be an important contributor to the endogenous rhythmical free water accrual and its modulation by dietary salt we observed in our subjects (36-38).

Summary. In summary, our ultra-long-term balance studies suggest that humans maintain water balance by endogenous rhythmical accrual and excretion of body water. Rhythmical mineralocorticoid regulation promotes $\mathrm{Na}^{+}$retention and osmolytefree water accrual by enhancing the water-economizing nature of the renal concentration mechanism $(39,40)$, resulting in increased body water. Contrariwise, rhythmical glucocorticoid release is associated with osmolyte excretion and inhibits the renal concentration mechanism in order to excrete surplus body water. This surplus had been accrued earlier, either by successful water conservation in the renal barrier, or by additional (unmeasured) water conservation in the extrarenal epithelial barriers, or, alternatively, by increasing the rate of (unmeasured) metabolic water generation. A 6-g/d increase in salt intake reduces rhythmical aldosterone and enhances rhythmical glucocorticoid action, increases endogenous osmolyte-free water accrual, and ultimately results in the excretion of surplus salt osmolytes, together with endogenously accrued surplus water. However, the accompanying relative predominance of rhythmical glucocorticoid release 
suggests that the maintenance of water homeostasis in states of surplus salt excretion is intimately coupled with changes in body energy expenditure in humans. Thus, salt-driven changes in energy metabolism may link high salt intake with diabetes mellitus (41-43), osteoporosis (44-48), and increased cardiovascular and neurovascular disease risk (49-54), even in the absence of any salt-sensitive blood pressure responses.

\section{Methods}

\section{Study subjects}

In the Mars105 and Mars520 space flight simulation studies, 12 healthy young male volunteers provided written informed consent following due approval to spend 105 and 520 days, respectively, in an enclosed habitat consisting of hermetically sealed interconnecting modules. The crews lived and worked like cosmonauts on the International Space Station. Environmental factors were maintained constant. Microgravity was not simulated. Anthropometric data on each participant are provided in Supplemental Table 1.

\section{Diets and the ultra-long balance approach}

Nutritional intervention took place during the complete Mars105 study and during the first 205 days of the simulated flight to Mars in the Mars520 study. Dietary salt intake was controlled throughout the study. Dietary salt reduction during the Mars105 study was performed stepwise from $12 \mathrm{~g} / \mathrm{d}$ to $9 \mathrm{~g} / \mathrm{d}$ to $6 \mathrm{~g} / \mathrm{d}$ salt. Given the longer duration of the Mars520 study, we could reexpose the subjects to $12 \mathrm{~g} / \mathrm{d}$ salt after salt depletion to $6 \mathrm{~g}$ /day salt (Supplemental Table 2). Each salt intake level was maintained constant for at least 29 days. Calorie intake necessary to satisfy energy expenditure with a moderately active lifestyle was permitted, and all other nutrients in the diet were maintained constant throughout the study. In contrast to salt intake, the subjects had unrestricted access to fluids, which included tap water, tea, coffee, juice, and milk. Monitoring of beverage consumption during the Mars520 study showed that the salt intake level had no influence on the subjects' beverage selection (Supplemental Table 3). The study subjects measured their fluid intake volumetrically and recorded each serving in their log books, which resulted in precise information on daily fluid intake. The subjects carefully collected 24-hour urine samples and measured their urine volume gravimetrically or volumetrically. Each subject was informed about the pitfalls of sodium and water balance studies and urine sampling in 4 separate 1-hour training sessions prior to the experiment. The subjects collected all their urine for a 24-hour period and each day transferred 4 aliquots of $10 \mathrm{ml}$, which were then frozen for later analysis. We defined inadequate caloric intake and lack of accuracy in daily sodium balance as dropout criteria. Accuracy was evaluated by individual average daily urinary sodium excretion as a percentage of the actual daily sodium intake. We excluded subjects from analysis when their weekly urinary sodium recovery was repeatedly less than $80 \%$ of sodium intake or when the subjects did not adhere to our daily menu plans. Only this strict focus on experimental accuracy allowed us to implement a longterm balance approach. Because 2 subjects did not comply with these criteria, we had to exclude them from further analysis.

\section{Data analysis}

Dietary salt intervention. We studied the dietary salt intervention by testing the effect of the prescribed salt intake phase (low salt intake: 6 $\mathrm{g} / \mathrm{d}$; medium salt intake: $9 \mathrm{~g} / \mathrm{d}$; high salt intake: $12 \mathrm{~g} / \mathrm{d}$ ) on the following: daily water intake and urine volume, with the result defined as the difference between measured fluid intake and urinary volume (water balance gap); urinary $\mathrm{Na}^{+}$, cortisone, and aldosterone excretion; urine $\mathrm{Na}^{+}, \mathrm{K}^{+}$, and urea concentration; and urine osmolality. We found that a reduction in salt intake from $12 \mathrm{~g} / \mathrm{d}$ to $6 \mathrm{~g} / \mathrm{d}$ affected our variables in a reversible fashion when salt intake was increased from $6 \mathrm{~g} / \mathrm{d}$ to $12 \mathrm{~g} / \mathrm{d}$ during the reexposure phase of the Mars520 experiment (Supplemental Table 4). Furthermore, the effects of a gradual reduction of initially high salt intake to low salt intake were comparable during the Mars105 and Mars520 studies (Supplemental Table 5). Recorded $\mathrm{Na}^{+}$intake and measured $\mathrm{Na}^{+}$excretion levels were approximately 10 to $20 \mathrm{mmol} / \mathrm{d}$ higher in the Mars105 experiment than in the Mars520 experiment. The 3 different salt intake levels resulted in the expected differences in average $\mathrm{UNaV}$ per salt phase, albeit with remarkable variability due to the previously reported day-to-day rhythmical variability in urine $\mathrm{Na}^{+}$excretion $(11,12,22)$. Therefore, we stratified our $\mathrm{UNaV}$ data into 3 tertiles - low (first tertile), medium (second tertile), and high (third tertile) $\mathrm{UNaV}$ - to test the effect of urine $\mathrm{Na}^{+}$excretion per UNaV tertile on our variables.

Effect of urine mineralocorticoid and glucocorticoid levels. Likewise, we stratified our 24-hour aldosterone and cortisone excretion data into 3 tertiles of low (first tertile), medium (second tertile), and high (third tertile) hormone levels. We then analyzed the changes in the variables per tertile for urine cortisone or aldosterone excretion. The metrics of the resulting tertiles are provided in Table 1.

Statistics. We first graphed the variables for each subject per unit of time. We next expressed the variables' average \pm SD per salt intake phase or per tertile of UNaV, urine cortisone excretion, or urine aldosterone excretion. We then investigated the salt phase- or tertileinduced changes $(\Delta)$ in the variables by mixed linear model analysis and depicted the estimated changes in the dependent variables as the estimated $\Delta \pm$ SEM. We found excellent agreement between the measured average \pm SD difference and the estimated \pm SEM change in the dependent variables. To facilitate data expression and interpretation, we primarily studied the effect of 6 -g/d versus $12-\mathrm{g} / \mathrm{d}$ salt intake and the effect of first tertile versus third tertile changes in $\mathrm{UNaV}$ as well as in urine cortisone and urine aldosterone excretion on water balance in humans. A $P$ value of less than 0.05 was considered statistically significant. SPSS software, version 21.0 (IBM) was used for statistical analysis. Detailed statistical analyses for each Figure and Table are provided in the Supplemental Materials.

\section{Study approval}

The isolation study was conducted at the Institute for Biomedical Problems in Moscow and approved by the Russian National Committee on Bioethics of the Russian Academy of Sciences, Physiology Panel, protocol numbers 241 (105-day study) and 269 (520-day study). All subjects provided informed consent prior to their participation in the study.

\section{Author contributions}

$\mathrm{NR}$ and LB performed the balance studies in Moscow. KK and AM analyzed and interpreted the data and wrote the manuscript. KL planned and performed the dietary intervention. AD planned and performed the electrolyte analyses. $\mathrm{AB}, \mathrm{SD}, \mathrm{CK}, \mathrm{TP}$, and $\mathrm{YZ}$ contributed to the data analysis and data interpretation. BJ participated in the mathematical analysis. MR planned and performed the 
hormone assays. DNM and FCL interpreted the data and wrote the manuscript. JT designed and supervised the study, organized and applied for grant funding, statistically analyzed and interpreted the data, and wrote the manuscript.

\section{Acknowledgments}

JT was supported by grants from the German Federal Ministry for Economics and Technology/DLR Forschung unter Weltraumbedingungen (50WB1624); the Interdisciplinary Centre for Clinical Research (IZKF Junior Research Group 2); the NIH (RO1 HL118579-01); the AHA (14SFRN20770008); and the Renal Research Institute. KK was supported by funding from the TOYO-
BO Biotechnology Foundation. The food products were donated by APETITO, Coppenrath und Wiese, ENERVIT, HIPP, Katadyn, Kellogg, Molda, and Unilever. No funding bodies had any role in study design, data collection and analysis, decision to publish, or preparation of the manuscript. We thank Ulrike Goller for technical assistance and Karl A. Kirsch for introducing the research topic in his "Man in Extreme Environment" seminar series in 1992.

Address correspondence to: Jens Titze, Division of Clinical Pharmacology, Vanderbilt University Medical Center, 2213 Garland Avenue, P435F MRBIV, Nashville, Tennessee 37232, USA. Phone: 615.343.1401; E-mail: jens.m.titze@vanderbilt.edu.
1. Kirkendall AM, Connor WE, Abboud F, Rastogi SP, Anderson TA, Fry M. The effect of dietary sodium chloride on blood pressure, body fluids, electrolytes, renal function, and serum lipids of normotensive man. J Lab Clin Med. 1976;87(3):411-434.

2. Palacios $\mathrm{C}$, et al. Sodium retention in black and white female adolescents in response to salt intake. J Clin Endocrinol Metab. 2004;89(4):1858-1863.

3. Titze J, et al. Long-term sodium balance in humans in a terrestrial space station simulation study. Am J Kidney Dis. 2002;40(3):508-516.

4. Heer M, Baisch F, Kropp J, Gerzer R, Drummer C. High dietary sodium chloride consumption may not induce body fluid retention in humans. Am J Physiol Renal Physiol. 2000;278(4):F585-F595.

5. Kopp C, et al. (23) Na magnetic resonance imaging of tissue sodium. Hypertension. 2012;59(1):167-172.

6. Kopp C, et al. 23Na magnetic resonance imaging-determined tissue sodium in healthy subjects and hypertensive patients. Hypertension. 2013;61(3):635-640.

7. Kopp C, et al. Seeing the sodium in a patient with hypernatremia. Kidney Int. 2012;82(12):1343-1344.

8. Dahlmann A, et al. Magnetic resonancedetermined sodium removal from tissue stores in hemodialysis patients. Kidney Int. 2015;87(2):434-441.

9. Jantsch J, et al. Cutaneous $\mathrm{Na}^{+}$storage strengthens the antimicrobial barrier function of the skin and boosts macrophage-driven host defense. Cell Metab. 2015;21(3):493-501.

10. Schneider MP, et al. Skin sodium concentration correlates with left ventricular hypertrophy in CKD [published online ahead of print February 2, 2017]. JAm Soc Nephrol. https://doi.org/ 10.1681/ ASN.2016060662.

11. Rakova N, et al. Long-term space flight simulation reveals infradian rhythmicity in human $\mathrm{Na}(+)$ balance. Cell Metab. 2013;17(1):125-131.

12. Lerchl K, et al. Agreement between 24-hour salt ingestion and sodium excretion in a controlled environment. Hypertension. 2015;66(4):850-857.

13. Walser M. Phenomenological analysis of electrolyte homeostasis. In: Seldin DW, Giebisch G, eds. The Kidney: Physiology and Pathophysiology (Vols 1-3). New York, New York: Raven Press, Ltd; 1992:31-34.

14. Pitts RF. Physiology of the Kidney and Body Fluids: An Introductory Text. Chicago, Illinois: Year Book
Medical Publishers; 1974:11-34.

15. Rose BD. In: Rose BD, ed. Clinical physiology of acid-base and electrolyte disorders. New York: McGraw-Hill Inc.; 1994:235-260.

16. Gunga HC, Maillet A, Kirsch K, Röcker L, Gharib C, Vaernes R. European isolation and confinement study. Water and salt turnover. Adv Space Biol Med. 1993;3:185-200.

17. He FJ, Markandu ND, Sagnella GA, MacGregor GA. Effect of salt intake on renal excretion of water in humans. Hypertension. 2001;38(3):317-320.

18. World Action on Salt \& Health. How does salt affect children? http://www.worldactiononsalt. com/salthealth/children/. Accessed March 2, 2017.

19. Grimes CA, Riddell LJ, Campbell KJ, Nowson CA. Dietary salt intake, sugar-sweetened beverage consumption, and obesity risk. Pediatrics. 2013;131(1):14-21.

20. Grimes CA, Wright JD, Liu K, Nowson CA, Loria CM. Dietary sodium intake is associated with total fluid and sugar-sweetened beverage consumption in US children and adolescents aged 2-18 y: NHANES 2005-2008. Am J Clin Nutr. 2013;98(1):189-196.

21. He FJ, Marrero NM, MacGregor GA. Salt intake is related to soft drink consumption in children and adolescents: a link to obesity? Hypertension. 2008;51(3):629-634.

22. Birukov A, et al. Ultra-long-term human salt balance studies reveal interrelations between sodium, potassium, and chloride intake and excretion. Am J Clin Nutr. 2016;104(1):49-57.

23. Yosipovitch G, Maayan-Metzger A, Merlob P, Sirota L. Skin barrier properties in different body areas in neonates. Pediatrics. 2000;106 (1 Pt 1):105-108.

24. Qi H, et al. Early diabetic kidney maintains the corticomedullary urea and sodium gradient. Physiol Rep. 2016;4(5):e12714.

25. Madias NE, Adrogue HJ. In: Davidson AM, ed. Oxford Textbook of Clinical Nephrology. New York: Oxford University Press; 2005:213.

26. McCance RA, Widdowson EM. The secretion of urine in man during experimental salt deficiency. J Physiol (Lond). 1937;91(2):222-231.

27. Titze J, Rakova N, Kopp C, Dahlmann A, Jantsch J, Luft FC. Balancing wobbles in the body sodium. Nephrol Dial Transplant. 2016;31(7):1078-1081.

28. Wilhelm KP, Cua AB, Maibach HI. Skin aging. Effect on transepidermal water loss, stratum corneum hydration, skin surface $\mathrm{pH}$, and casual sebum content. Arch Dermatol.
1991;127(12):1806-1809.

29. Luft FC, Fineberg NS, Sloan RS, Hunt JN. The effect of dietary sodium and protein on urine volume and water intake. J Lab Clin Med. 1983;101(4):605-610.

30. Danzinger J, Zeidel M, Parker MJ, Schwartzstein RM. Renal Physiology: A Clinical Approach. Pennsylvania, PA: LLW; 2012:232.

31. [No authors listed]. Intersalt: an international study of electrolyte excretion blood pressure. Results for 24 hour urinary sodium and potassium excretion. Intersalt Cooperative Research Group. BMJ.1988;297(6644):319-328.

32. Cobb LK, et al. Methodological issues in cohort studies that relate sodium intake to cardiovascular disease outcomes: a science advisory from the American Heart Association. Circulation. 2014;129(10):1173-1186.

33. Perucca J, Bouby N, Valeix P, Bankir L. Sex difference in urine concentration across differing ages, sodium intake, and level of kidney disease. Am J Physiol Regul Integr Comp Physiol. 2007;292(2):R700-R705.

34. Kerstens MN, et al. Salt loading affects cortisol metabolism in normotensive subjects: relationships with salt sensitivity. JClin Endocrinol Metab. 2003;88(9):4180-4185.

35. Kottner J, Lichterfeld A, Blume-Peytavi U. Transepidermal water loss in young and aged healthy humans: a systematic review and meta-analysis. Arch Dermatol Res. 2013;305(4):315-323.

36. Gizowski C, Zaelzer C, Bourque CW. Clockdriven vasopressin neurotransmission mediates anticipatory thirst prior to sleep. Nature. 2016;537(7622):685-688.

37. Mandelblat-Cerf Y, et al. Bidirectional anticipation of future osmotic challenges by vasopressin neurons. Neuron. 2017;93(1):57-65.

38. Oka Y, Ye M, Zuker CS. Thirst driving and suppressing signals encoded by distinct neural populations in the brain. Nature. 2015;520(7547):349-352.

39. Steinmetz PR, Smith HW. Urea and the renal concentrating operation in man. Am JMed. 1963;35:727-736.

40. Gamble JL, McKhann CF, Butler AM, Tuthill E. An economy of water in renal function referable to urea. Am J Physiol. 1934;109(1):139-154.

41. Liu H, Bravata DM, Cabaccan J, Raff H, Ryzen E. Elevated late-night salivary cortisol levels in elderly male type 2 diabetic veterans. Clin Endocrinol (Oxf). 2005;63(6):642-649.

42. Mullan $\mathrm{K}$, et al. Is there value in routine screening 
for Cushing's syndrome in patients with diabetes? JClin Endocrinol Metab. 2010;95(5):2262-2265.

43. Newsome S, Chen K, Hoang J, Wilson JD, Potter JM, Hickman PE. Cushing's syndrome in a clinic population with diabetes. Intern Med J. 2008;38(3):178-182.

44. Chiodini I, et al. Spinal volumetric bone mineral density and vertebral fractures in female patients with adrenal incidentalomas: the effects of subclinical hypercortisolism and gonadal status. JClin Endocrinol Metab. 2004;89(5):2237-2241.

45. Chiodini I, et al. Bone mineral density, prevalence of vertebral fractures, and bone quality in patients with adrenal incidentalomas with and without subclinical hypercortisolism: an Italian multicenter study. JClin Endocrinol Metab. 2009;94(9):3207-3214.

46. Chiodini I, et al. Eugonadal male patients with adrenal incidentalomas and subclinical hypercortisolism have increased rate of vertebral frac- tures. Clin Endocrinol (Oxf). 2009;70(2):208-213. 47. Morelli V, et al. Risk of new vertebral fractures in patients with adrenal incidentaloma with and without subclinical hypercortisolism: a multicenter longitudinal study. J Bone Miner Res. 2011;26(8):1816-1821.

48. Tauchmanovà L, et al. Effects of sex steroids on bone in women with subclinical or overt endogenous hypercortisolism. Eur JEndocrinol. 2007;157(3):359-366.

49. Güder G, et al. Complementary and incremental mortality risk prediction by cortisol and aldosterone in chronic heart failure. Circulation. 2007;115(13):1754-1761.

50. Marklund N, Peltonen M, Nilsson TK, Olsson T. Low and high circulating cortisol levels predict mortality and cognitive dysfunction early after stroke. J Intern Med. 2004;256(1):15-21.

51. Smith GD, Ben-Shlomo Y, Beswick A, Yarnell J, Lightman S, Elwood P. Cortisol, testosterone, and coronary heart disease: prospective evidence from the Caerphilly study. Circulation. 2005;112(3):332-340.

52. Vogelzangs N, Beekman AT, Milaneschi Y, Bandinelli S, Ferrucci L, Penninx BW. Urinary cortisol and six-year risk of all-cause and cardiovascular mortality. JClin Endocrinol Metab. 2010;95(11):4959-4964.

53. Di Dalmazi G, et al. Cardiovascular events and mortality in patients with adrenal incidentalomas that are either non-secreting or associated with intermediate phenotype or subclinical Cushing's syndrome: a 15-year retrospective study. Lancet Diabetes Endocrinol. 2014;2(5):396-405.

54. Di Dalmazi G, et al. Progressively increased patterns of subclinical cortisol hypersecretion in adrenal incidentalomas differently predict major metabolic and cardiovascular outcomes: a large cross-sectional study. Eur J Endocrinol. 2012;166(4):669-677. 